\title{
A Comparative Study of Five Different Methods for the Determination of 3-Methoxy-4-hydroxymandelic Acid in Urine
}

\author{
By C. G. Thomasson'), B. G. Blijenberg
}

Department of Clinical Chemistry, University Hospital Rotterdam Dijkzigt, and Department of Chemical Pathology, Erasmus University, Rotterdam, The Netherlands

\section{G. A. M. Eilers}

Institute of Biostatistics, Erasmus University, Rotterdam, The Netherlands and

\section{B. Leijnse}

Department of Clinical Chemistry, University Hospital Rotterdam Dijkzigt, and Department of Chemical Pathology, Erasmus University, Rotterdam, The Netherlands

(Received September 22/December 27. 1982)

Summary: Five different methods for the determination of 3-methoxy-4-hydroxymandelic acid (vanilmandelic acid, VMA) in urine were compared: a GLC-FID catecholamine metabolite profiling method, an HPLC method with electrochemical detection, the method of Pisano et al. ((1962) Clin. Chim. Acta 7, 285-291), a one dimensional paper chromatographic method with diazotized $p$-nitroaniline staining and the commercially available Bio-Rad VMA by Column Test. The comparison consisted of an imprecision study, a linearity check, a recovery study, a split sample comparison and an interference study. The best results of the imprecision study $(\mathrm{n}=8)$ were found with the Bio-Rad and the HPLC method (within-run imprecision had a coefficient of variation $(\mathrm{CV})$ of $5.1 \%$ and $1.4 \%$; between-days $\mathrm{CV}$ of $5.9 \%$ and $6.0 \%$ respectively for values of $32.4 \mu \mathrm{mol} / \mathrm{l}$ and $24.5 \mu \mathrm{mol} / \mathrm{l})$. The Pisano method had the poorest within-run $\mathrm{CV}(14.6 \%)$ and between-days CV $(16.8 \%)$ for a value of $23.2 \mu \mathrm{mol} / 1$. All methods showed good linearity. The mean recovery of the HPLC method was $101.3 \%$; the mean recovery of the other four methods ranged from $93.9 \%-96.0 \%$. The split sample comparison showed that the accuracy of the HPLC, the GLC and the Pisano method is comparable. The accuracy of the paper chromatographic method and the Bio-Rad method had a positive bias compared with the HPLC method. Especially the positive bias of the Bio-Rad method can be very large. The HPLC method was not influenced by the compounds tested in the interference study, whereas the GLC method in some cases only suffered from overloading problems. The Pisano and the Bio-Rad method were most influenced by the interfering compounds tested. We conclude that the HPLC and the GLC methods are superior to the other three VMA methods. From an analytical point of view HPLC is the method of choice for determining 3-methoxy-4-hydroxymandelic acid in urine.

Vergleichende Untersuchung von fünf verschiedenen Methoden zur Bestimmung von 3-Methoxy-4-hydroxymandelsäure im Harn

\section{Zusammenfassung:}

Fünf verschiedene Methoden zur Bestimmung von 3-Methoxy-4-hydroxymandelsäure (Vanillinmandelsäure, VMA) im Harn werden verglichen:

1. Gaschromatographische Methode mit Flammenionisations-Detektion zur Erstellung von Catecholaminmetabolit-Profilen.

1) Present adress: Algemeen Ziekenhuis "de Tjongersschans", Thialfweg 44, NL-8441 PW Heerenveen. The Netherlands. 
2. Hochleistungsflüssigchromatographische (HPLC) Methode mit elektrochemischer Detektion.

3. Methode nach Pisano ((1962) Clin. Chim. Acta 7, 285-291).

4. Eindimensionale papierchromatographische Methode mit Detektion durch diazotiertes $p$-Nitroanilin.

5. Säulen-Test Bio-Rad VMA. $\cdot 1$

Der Vergleich umfaßte:

a) Untersuchungen zur Präzision $(n=8)$

Die besten Ergebnisse wurden mit der Bio-Rad und der HPLC-Methode erżielt: VK in der Serie 5;1\% und 1,4\%; VK von Tag zu Tag 5,9\% und 6,0\%; $c=32,4$ und 24,5 $\mu \mathrm{mol} / 1$. Die Pisano-Methode hatte die schlechteste Präzision: VK in der Serie 14,6\%; VK von Tag zu Tag $16,8 \% ; c=23,2 \mu \mathrm{mol} / \mathrm{A}$.

b) Linearitätsprüfung

Alle Methoden wiesen eine gute Linearität auf.

c) Untersuchungen zur Wiederfindung

Die mittlere Wiederfindung der HPLC-Methode betrug 101,3\%, die der anderen 4 Methoden 93,9-96,0\%.

d) Prüfung der Richtigkeit durch Vergleich an der geteilten Probe

Die Richtigkeit von HPLC-, gaschromatographischer und Pisano-Methode ist vergleichbar. Papierchromatographische und Bio-Rad-Methode zeigten, verglichen mit der HPLC-Methode, eine positive Abweichung, die besonders bei der Bio-Rad-Methode sehr hoch sein kann.

e) Untersuchungen von Störeinflüssen

Die HPLC-Methode wurde durch die geprüften Verbindungen nicht gestört, während die gaschromatographische Methode manchmal unter Überladungsproblemen litt. Die Pisano- und die Bio-Rad-Methode zeigten die häufigsten Störungen durch die geprüften Substanzen.

Schlußfolgerung: HPLC und Gaschromatographie sind żur Bestimmung von 3-Methoxy-4-hydroxymandel= säure vorteilhafter als die anderen drei Methoden. Vom analytischen Standpunkt ist die HPLC die Methode der Wahl zur Bestimmung von 3-Methoxy-4-hydroxymandelsäure im Harn.

\section{Introduction}

In 1957 Armstrong et. al. $(1,2)$ discovered that the excretion of 3-methoxy-4-hydroxymandelic acid (vanilmandelic acid) is increased in the urine of pheochromocytoma patients. Nowadays we know that it is one of the main metabolites of the catecholamines norepinephrine and epinephrine. Together with 3-methoxy-4-hydroxyphenylethyleneglycol it accounts for about $80 \%$ of the overall turnover of norepinephrine and epinephrine (3). Its determination, together with other urinary catecholamine metabolites is important in the diagnosis and the follow up of patients with neural crest tumors (neuroblastoma, ganglioneuroblastoma and pheochromocytoma).

Amstrong et al. determined the urinary excretion of 3-methoxy-4-hydroxymandelic acid with a method based on organic solvent extraction, two dimensional paper chromatography and staining with diazotised $p$-nitroaniline (4). In the years following their discovery other quantitative methods were described
(5-7). One of these, the method of Pisano et al. (7), based on organic solvent extraction and photometry of vanillin, the oxidation product of vanilmandelic acid, is still in use in many clinical chemical laboratories. In the last decade several articles have been published concerning the results of 3-methoxy-4-hydroxymandelic acid determinations using gas liquid chromatography (GLC) with flame ionisation detection $(8-15)$ or electron capture detection $(16,17)$. More recently high performance liquid chromatography (HPLC) procedures with ultra violet detection $(18,19)$, fluorescence detection $(20,21)$, electrochemical detection $(22-27)$ or a periodate oxidative monitor $(28,29)$ were described. As stated by the authors, the reasons for using GLC or HPLC are: saving of time, possibility of multicomponent determination and improvement of precision, sensitivity and specificity. Although theoretically this last argument may be valid, little practical evidence is presented. In only half of the articles cited, the authors compared their GLC or HPLC method with a classical one, mostly the Pisano method $(8,10,15,20,22$, 
23, 27-29) and sometimes a two dimensional paper chromatographic method $(18,19)$. In merely half of the cited articles imprecision data are given $(10-12$, $14,15,20,23,25,27-29)$. With the exception of 1.c. (25), these articles fail to present imprecision data of the classical vanilmandelic acid method when a split sample comparison was carried out. This lack of quality control and split sample comparison data make it difficult to compare different 3-methoxy-4hydroxymandelic acid methods. Therefore we made a comparison, including these items, between two modern 3-methoxy-4-hydroxymandelic acid procedures (the GLC catecholamine metabolite profiling method described by Muskiet et al. (14) and a modification by Moleman \& Borstrok (30) of the HPLC method of Morrisey \& Shihabi (23)), two classical 3methoxy-4-hydroxymandelic acid determinations (the method of Pisano et. al. (7) and an one dimensional paper chromatographic procedure comparable with the method described by Vahidi (31)) and one commercially available 3-methoxy-4-hydroxymandelic acid test (the Bio-Rad VMA by Column Test).

It is known that for a urinary 3-methoxy-4-hydroxymandelic acid determination the patient must keep to a certain diet and stop medication. Therefore we were also interested in establishing the influence of various compounds which are known to interfere in the different methods in a methodological way, according to the compilation of Young et al. (32). This investigation together with the comparison study was carried out by mailing urine samples to five different laboratories, each performing one of the five methods mentioned above and having sufficient experience with this method.

\section{Materials and Methods}

The following chemicals, 3-methoxy-4-hydroxymandelic acid standard, control urine and urine samples were used for preparing different samples of the comparison study.

\section{Chemicals}

4-Hydroxy-3-methoxymandelic acid (vanilmandelic acid, VMA), 4-hydroxy-3-methoxyphenylacetic acid '(homovanillic acid, HVA), p-hydroxymandelic acid, 4-hydroxy-3-methoxybenzoic acid (vanillic acid) and salicyluric acid were purchased from Sigma Chemical Co., St. Louis, M.O. 63178.

2,5-Dihydroxybenzoic acid (gentisic acid), p-aminosalicylic acid, 5-hydroxy-indoleacetic acid; glycerylguaiacolate and tetrabromophenolsulphonephthalein (Bromthalein) were from Merck, Darmstadt, FRG.

2,5-Dihydroxyphenylacetic acid (homogentisic acid) and phenolsulphonephthalein were from Fluka AG, CH-9470 Buchs, Switzerland.

3,4-Dihydroxyphenylacetic acid was from Labkemi, Stockholm, Sweden.

\section{3-Methoxy-4-hydroxymandelic acid standard}

A $100 \mu \mathrm{mol} / \mathrm{A}$ standard was prepared in $0.05 \mathrm{~mol} / \mathrm{l}$ hydrochloric acid solution and in part diluted to $50 \mu \mathrm{mol} / /$ with $0.05 \mathrm{~mol} / \mathrm{l} \mathrm{hy}-$ drochloric acid solution.

\section{Control urine}

The lyophilized control urine I (lot. No. 090V02) and control urine II (lot. No. 1V214) both from Ortho Diagnostic Inc. Rariton, New Jersey 08869 , were reconstituted with distilled water. A mixture of 30 vials of control urine I and 9 vials of control urine II was aliquoted and stored at $-20^{\circ} \mathrm{C}$. This mixture was used as a control urine.

\section{Urine samples}

All urine samples, collected after the patients had kept to a diet (no coffee, tea, cola drinks, bananas, vanillin and products flavoured with vanillin) were preserved by acidification to $\mathrm{pH} 1.0$ with hydrochloric acid. The samples were aliquoted and stored at $-20^{\circ} \mathrm{C}$ until they were distributed.

\section{Sample distribution}

During a six month period we distributed by mail every two weeks a series of urine samples. In total 12 series containing 106 samples were distributed. The urine samples in each series were randomized using a table of permutations. On arrival the thawed samples were stored at $4^{\circ} \mathrm{G}$ when the 3-methoxy-4-hydroxymandelic acid determination could be performed within two days. Otherwise the samples were frozen.

Imprecision study and split sample comparison

Twelve different urine samples were divided in two groups of six samples. Each group, completed with two samples of the control urine, was distributed four times, resulting in eight series. The results of these sixtyfour 3-methoxy-4-hydroxymandelic acid determinations, four determinations in twelve different urine samples and eight determinations in duplicate of the control urine, were used for the split sample comparison and the imprecision study.

\section{Linearity check}

Linearity was checked with a series of nine samples, consisting of a urine with a low $( \pm 10 \mu \mathrm{mol} / \mathrm{l})$ and one urine with a high $( \pm 100$ $\mu \mathrm{mol} / 1$ ) 3-methoxy-4-hydroxymandelic acid content and mixtures of these two urines having high/low ratios (by volume) of 1/7.2/6, $3 / 5,4 / 4,5 / 3,6 / 2$ and $7 / 1$.

\section{Recovery study}

For the recovery study the same urine sample with a low content from the linearity check was enriched with the following 3-methoxy-4-hydroxymandelic acid concentrations: $20,40,60.80$ and $100 \mu \mathrm{mol} / 1$ urine.

\section{Interference study}

A pool urine was aliquoted and to separate aliquots one of the following compounds was added per liter of pool urine: $2000 \mathrm{mg}$ of homogentisic acid; $1000 \mathrm{mg}$ of gentisic acid, homovanillic acid. vanillic acid, salicyluric acid, glycerylguaiacolate, $p$-aminosalicylic acid; $500 \mathrm{mg}$ of 3,4-dihydroxyphenylacetic acid, 5-hydroxyindoleacetic acid; $100 \mathrm{mg}$ of $p$-hydroxymandelic acid; $6 \mathrm{mg}$ of phenolsulphonephthalein;350 mg of Bromthalein.

\section{The GLC method}

Single determinations were performed with the method according to Muskiet et al. (14), with the following modifications:

a) after injection the gas chromatograph was programmed from $120^{\circ} \mathrm{C}$ to $200{ }^{\circ} \mathrm{C}$ at $16^{\circ} \mathrm{C} / \mathrm{min}$ followed by $3^{\circ} \mathrm{C} / \mathrm{min}$ to $260^{\circ} \mathrm{C}$ and $15 \mathrm{~min}$ at $260^{\circ} \mathrm{C}$. 
b) $0.25 \mathrm{ml}$ of $\mathrm{n}$-alkane $C_{2 x}$ solution $(0.5 \mathrm{mmol} / 1$ hexane) was added to the urine sample before the extraction with ethyl acetate, as a check for the efficiency of the derivatization of the internal standard propylgallate.

\section{The HPLC method}

The HPLC method was a modification by. Moleman \& Borstrok(30) of the procedure of Morrisey \& Shihabi (23). The following alterations were applied:

a) $1 \mathrm{ml}$ of urine was diluted with $1 \mathrm{ml}$ of $1 \mathrm{~mol} / /$ citric acid, containing $5 \mathrm{~g}$ EDTA and $5 \mathrm{~g} \mathrm{Na}_{2} \mathrm{~S}_{2} \mathrm{O}_{5}$ per litre and extracted with $8 \mathrm{ml}$ of ethyl acetate; the ethyl acetate layer was extracted with $4 \mathrm{ml}$ of $0.1 \mathrm{~mol} / 1 \mathrm{Na}_{2} \mathrm{HPO}_{4} \mathrm{pH} 8.5$, containing $5 \mathrm{~g}$ EDTA and $5 \mathrm{~g} \mathrm{Na}_{2} \mathrm{~S}_{2} \mathrm{O}_{5}$ per litre; after removing the ethyl acetate $50 \mu \mathrm{l}$ of $700 \mathrm{~g} / \mathrm{kg} \mathrm{HClO}+$ was added;

b) $50 \mu \mathrm{l}$ of the acidified phosphate extract was injected;

c) for elution a linear gradient from $2.5 \mathrm{ml}$ to $47.5 \mathrm{ml}$ propanol in 1 litre $0.05 \mathrm{~mol} / / \mathrm{Na}_{2} \mathrm{HPO}_{4}\left(\mathrm{pH} 2.7\right.$ with $\left.\mathrm{HClO}_{4}\right)$ in $10 \mathrm{~min}$ was used with a flow rate of $2 \mathrm{ml} / \mathrm{min}$; the reequilibration time was $5 \mathrm{~min}$;

d) the oxidation potential was maintained at $+0.8 \mathrm{~V}$ vs. $\mathrm{Ag} /$ $\mathrm{AgCl}$;

e) quantification was performed by constructing a calibration curve using four 3-methoxy-4-hydroxymandelic acid concentrations in the range of $10-100 \mu \mathrm{mol} / \mathrm{l}$, after the extraction described under modification a). based on calculation by area.

The following equipment was used: automatic liquid chromatograph with an autosampler and integrator (Hewlett-Packard 1084 B or Spectra Physics 8100-4100) with an electrochemical detector (Bioanalytical Systems), consisting of an LC -4 controller and a $\mathrm{TL}-5$ cell (glassy carbon electrode and $\mathrm{Ag} / \mathrm{AgCl}$ reference electrode). The sensitivity was set at $50 \mathrm{nA} / \mathrm{V}$. A filtering of $2 \mathrm{~s}$ was used. An analytical column, $15 \mathrm{~cm} \times 4.6 \mathrm{~mm}$ I.D.-packed with Hypersil ODS, $5 \mu \mathrm{m}$ particle size. was obtained from Chrompack, Middelburg, The Netherlands. The eluents were filtered through Millipore filters of pore size of $0.45 \mu \mathrm{m}$ and continuously degassed with helium. The detector response (peak area) and the retention time were calibrated every six samples with a 3-methoxy-4-hydroxymandelic acid standard solution injected directly into the chromatograph. All determinations were performed in duplicate.

In this way it is possible to analyse 30 to 40 urine samples in duplicate in 24 hours.

The lifetime of the reference electrode and the analytical column are about two years. The number of plates are halved during these two years by several thousand determinations.

\section{The Pisano method}

The method of Pisano et al. (7) was performed with one slight modification: all volumes (starting with $2.5 \mathrm{ml}$ of urine) were reduced by half, with the exception of the volumes of the reagents used for the oxidation with $\mathrm{NaIO}_{4}$, the reduction with $\mathrm{Na}_{2} \mathrm{~S}_{2} \mathrm{O}_{5}$ and the neutralization with acetic acid and phosphate buffer. The method was performed in duplicate with regard to the unknown; the urine blanks were single determinations.

\section{The Bio-Rad VMA by Column Test}

The Bio-Rad VMA by Column Test was performed according to the manufacturer's instructions (33). Only with the determination of the 3-methoxy-4-hydroxymandelic acid standard the concentration of $\mathrm{Na}_{2} \mathrm{~S}_{2} \mathrm{O}_{5}$ was 20 times higher than normal. All urine samples were analysed in duplicate. At the end of this comparison study the Bio-Rad VMA by Column Test was no longer available. because of production problems.
The one dimensional paper chromatographic method

The one dimensional paper chromatographic method was developed by Molenaar ( Department of Chemical Pathology, University of Leiden. The Netherlands) (34) and is comparable with the method published by Vahidi et al. (31).

Statistics

i

Performing two determinations with the control urine, both in duplicate, in the same series, on eight differient days, we have the following sources of variance:

$\hat{\sigma}_{b d}^{2}$ : the variance between the eight days (with seven degrees of freedom)

$\hat{\sigma}_{w d}^{2}:$ the variance within each day, between the two determinations (with eight degrees of freedom)

$\hat{\sigma o d u}_{\mathrm{du}}$ : the variance within each day, between the sixteen duplicates (with sixteen degrees of freedom)

We obtained these variances with a two way or three way variance analysis (35) and calculated the within-run and between-days coefficient of variation as follows:

within-run $\mathrm{CV}=$

$$
\frac{\sqrt{\hat{\sigma}_{\mathrm{wd}}^{2}+\frac{\hat{1}}{2} \hat{\sigma}_{d u}^{2}}}{\text { mean }} \times 100(\%)
$$

(if $\mathrm{n}=8$ :

8 times 1 determination in duplicate on the same day)

between-days $C V=\frac{\sqrt{\hat{\sigma}_{b d}^{2}+\hat{\sigma}_{\mathrm{wd}}^{2}+\frac{1}{2} \hat{\sigma}_{d u}^{\partial}}}{\text { meạn }} \times 100(\%)$

(if $\mathrm{n}=8$ :

1 determination in duplicate on 8 days).

\section{Results}

\section{Standardization}

Table 1 shows the values found for the two distributed 3-methoxy-4-hydroxymandelic acid standards, when each method was performed using its own standard(s) for quantification.

\section{Imprecision study}

The results of the between-days imprecision and the within-run imprecision of the five methods are given in table 2. Also the estimates of the variances of three different sources (between-days $\hat{\sigma}_{b d}^{2}$, withindays between-determinations $\hat{\sigma}_{w d}^{2}$ and within-days between-duplicates $\hat{\sigma}_{\mathrm{du}}^{2}$ ) are shown. $\hat{\sigma}_{d u}^{2}$ of the GLC method is not known, because this method was not performed in duplicate.

\section{Linearity check}

The results of the linearity check are presented in table 3 as linear regression equations, together with the number of samples (n) and the correlation coefficient $(r)$. 
Tab. 1. Values found for two 3-methoxy-4-hydroxymandelic acid standards by the five methods.

3-methoxy-4-hydroxymandelic acid $(\mu \mathrm{mol} / \mathrm{l})$ found

\begin{tabular}{rlrrrr}
$\begin{array}{l}\mu \mathrm{mol} / 1 \\
\text { Standard }\end{array}$ & GLC & Bio-Rad Pisano & $\begin{array}{l}\text { Paper- } \\
\text { chromatography }\end{array}$ \\
\hline 50 & $\left.46.8^{*}\right)$ & 53.4 & 50.4 & 46.0 & 48.5 \\
100 & $\left.87.8^{*}\right)$ & 99.2 & 103.6 & 96.0 & 100.3
\end{tabular}

*) The standards are taken through the entire analytical procedure and calibration is done with a standard not taken through the entire procedure.

\section{Recovery}

In table 4 the results of the recovery experiments are shown. The mean analytical recovery $\pm 1 \mathrm{SD}$, together with the results of the linear regression analysis, are given.

\section{Split sample comparison}

Figures $1 \mathrm{a}-\mathrm{d}$ give the results of the comparison of the 3-methoxy-4-hydroxymandelic acid concentrations found in thirteen urines with all five methods.

Tab. 2. Results of imprecision study with the five methods $(n=8)$

\begin{tabular}{|c|c|c|c|c|c|}
\hline & GLC & Bio-Rad & Pisano*) & Paperchromatography & HPLC \\
\hline $\begin{array}{l}\text { 3-methoxy-4-hydroxymandelic acid } \\
\text { mean }(\mu \mathrm{mol} /)\end{array}$ & 20.0 & 32.4 & $23.2(24.6)$ & 30.0 & 24.5 \\
\hline ôd̆ & - & 0.63 & $0.60 \quad(0.60)$ & 2.36 & 0.24 \\
\hline$\hat{\sigma}_{\bar{u} d}^{2}$ & 1.12 & 2.41 & $11.22(1.65)$ & 5.63 & 0) \\
\hline$\hat{\sigma}_{k d}^{z}$ & 6.50 & 0.94 & $3.67(0.31)$ & 5.81 & 2.01 \\
\hline$\hat{\sigma}_{\text {toutal }}^{2}$ & 7.62 & 3.66 & $15.19 \quad(2.26)$ & 12.62 & 2.13 \\
\hline Within-run CV (\%) & 5.3 & 5.1 & $(5.7)$ & 8.7 & 1.4 \\
\hline Between-days CV (\%) & 13.8 & 5.9 & $(6.1)$ & 11.8 & 6.0 \\
\hline
\end{tabular}

*) Results betwcen brackets are corrected for too high urine blanks.

Tab. 3. Results of the linearity check with the five methods.

For the linear regression analysis: $x=1$ is the low, $x=9$ is the high urine sample (see Materials and Methods under linearity check); $y$ is the amount of 3-methoxy-4-hydroxymandelic acid found by the five methods; $n$ is the number of urine samples; $r$ is the correlation coefficient.

\begin{tabular}{llll}
\hline Method & Linear regression line & $\mathrm{n}$ & $\mathrm{r}$ \\
\hline GLC & $\mathrm{y}=-1.1+8.12 \times$ & 8 & 0.9944 \\
Bio-Rad & $\mathrm{y}=11.0+9.95 \times$ & 9 & 0.9943 \\
Pisano & $\mathrm{y}=1.2+10.71 \times$ & 9 & 0.9993 \\
Paperchromatography & $\mathrm{y}=-2.0+12.54 \mathrm{x}$ & 9 & 0.9959 \\
HPLC & $\mathrm{y}=-3.7+11.78 \mathrm{x}$ & 9 & 0.9987 \\
\hline
\end{tabular}

Twelve urines were analysed four times and one urine (the control urine of the imprecision study) was analysed sixteen times (eight times in duplicate). The means of these values were used for the linear regression analysis. The results are given with the HPLC method selected as the reference method, because of the good results of the imprecision, linearity, recovery and interference study (see Discussion).

In table 5 we summarized different linear regression lines (no. 1-12), obtained by varying the reference method (HPLC or Pisano method) and the concentration unit of 3-methoxy-4-hydroxymandelic acid

Tạb. 4. Results of the recovery study with the five methods.

A urine with low 3-methoxy-4-hydroxymandelic acid content was enriched with the following 3-methoxy-4-hydroxymandelic acid concentrations: $20,40,60,80$ and $100 \mu \mathrm{mol} / \mathrm{l}$ urine.

For the linear regression analysis: $x$ is the added amount of 3-methoxy-4-hydroxymandelic acid; $y$ is the amount of 3-methoxy-4hydroxymandelic acid found by the five methods; $n$ is the number of urine samples; $r$ is the correlation coefficient.

\begin{tabular}{|c|c|c|c|c|}
\hline Method & Mean recovery $\pm 1 S D$ & Linear regression line & $\mathrm{n}$ & $r$ \\
\hline $\begin{array}{l}\text { GLC } \\
\text { Bio-Rad } \\
\text { Pisano } \\
\text { Paperchromatography } \\
\text { HPLC }\end{array}$ & $\begin{array}{r}95.7 \pm 9.1 \\
96.0 \pm 3.3 \\
94.4 \pm 2.1 \\
93.9 \pm 2.6 \\
101.3 \pm 1.3\end{array}$ & $\begin{array}{l}y=6.8+0.98 x \\
y=15.0+1.00 x \\
y=6.6+0.98 x \\
y=10.2+0.94 x \\
y=7.5+1.01 x\end{array}$ & $\begin{array}{l}6 \\
5 \\
6 \\
6 \\
6\end{array}$ & $\begin{array}{l}0.9932 \\
0.9993 \\
0.9981 \\
0.9990 \\
0.9994\end{array}$ \\
\hline
\end{tabular}


( $\mu \mathrm{mol} / /$ or $\mu \mathrm{mol} / 24 \mathrm{~h}$ ) and by correcting for the recovery differences. We also give four linear regression lines found in the literature (no. 13-16).

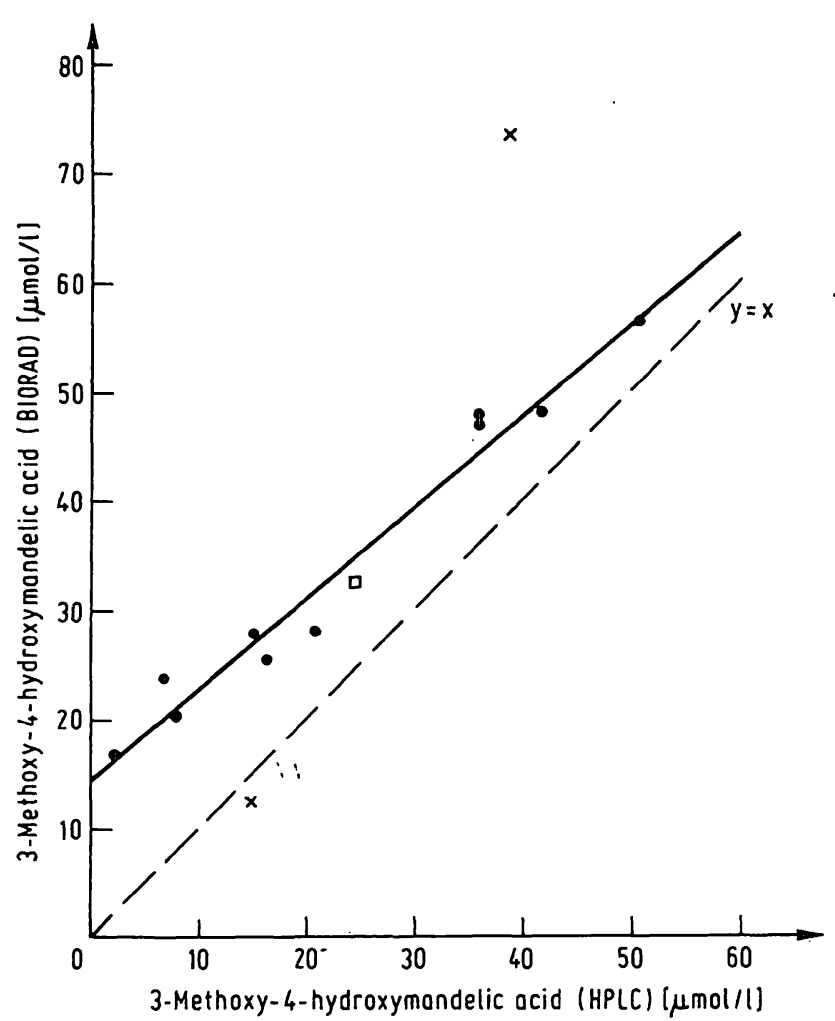

Fig. 1a. Linear regression analysis: $y($ Bio-Rad $)=14.5+0.83 \times($ HPLC $) ; n=11 ; r=0.9829$.

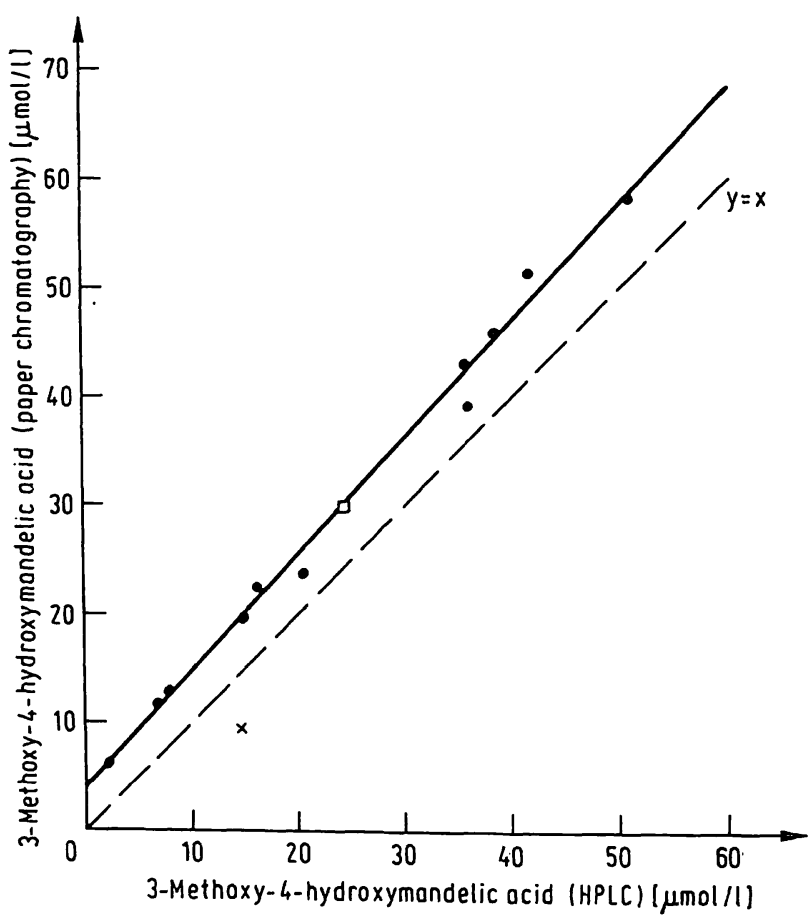

Fig. 1c. Linear regression analysis:

$\mathrm{y}($ Paperchromatography $)=3.9+1.07 \times($ HPLC $) ; \mathrm{n}=$

\section{Interference study}

The in vitro influence of twelve compounds on the five methods are presented in table 6 . The results are the mean of two determinations.

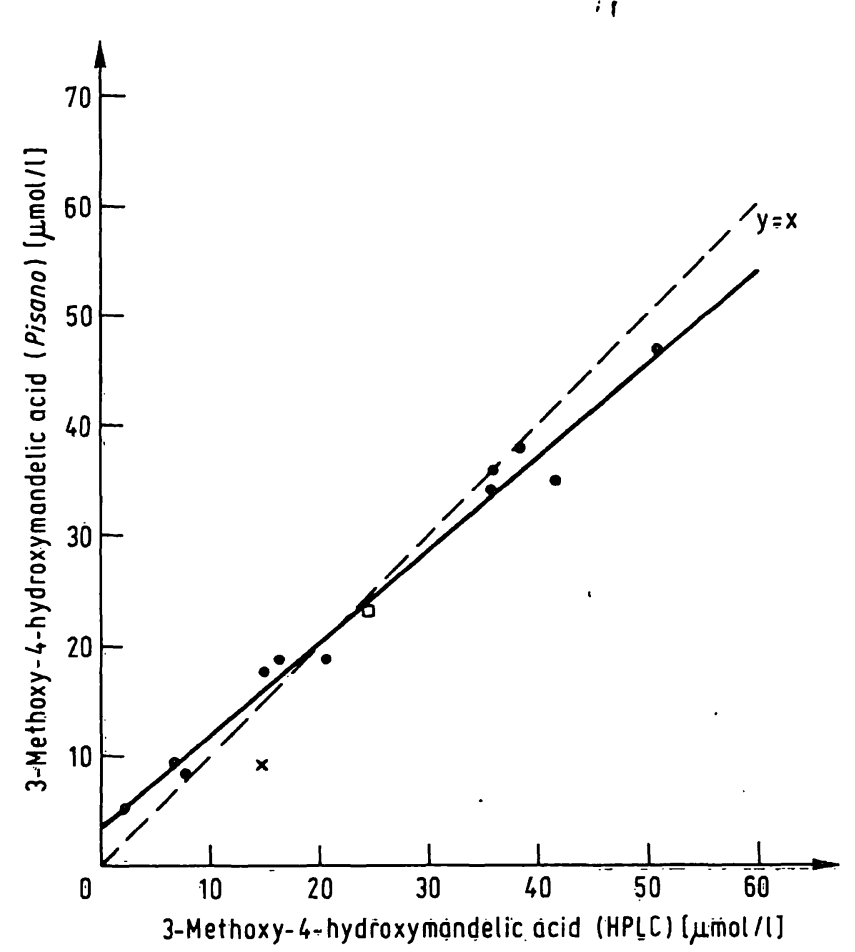

Fig. 1b. Linear regression analysis: $y($ Pisano $)=3.5+0.84 \times($ HPLC $) ; n=12 ; r=0.9912$.

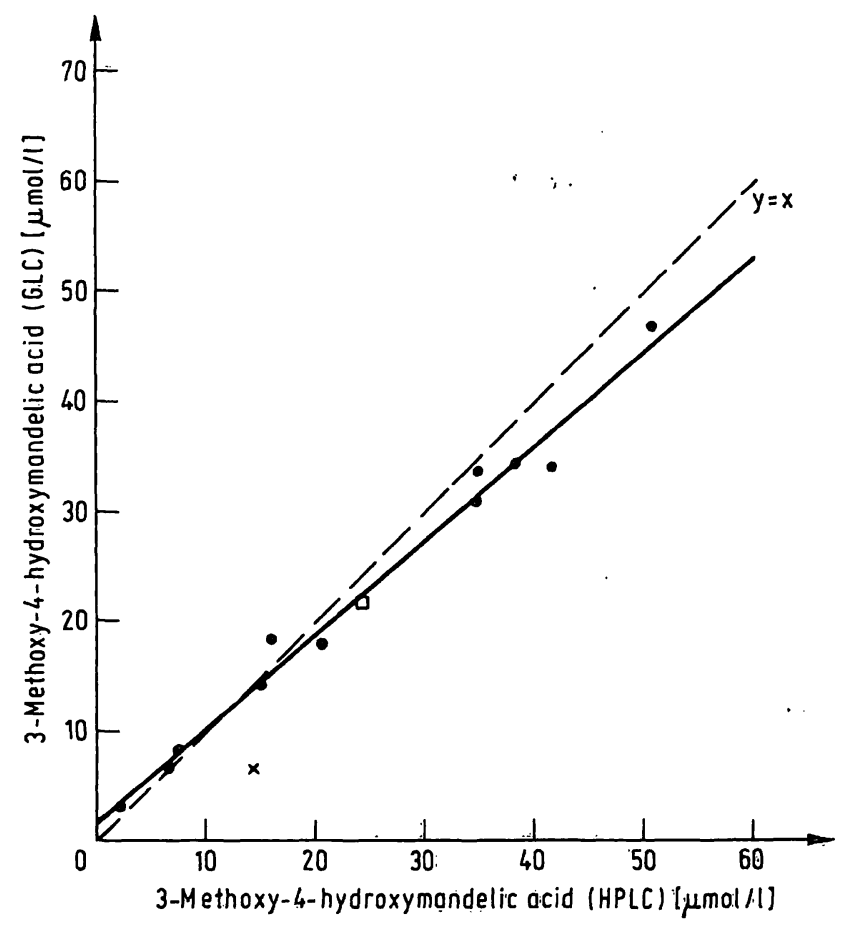

Fig. 1d. Linear regression analysis: $y(G L C)=1.6+0.85 x($ HPLC $) ; n=12 ; r=0.9929$

Fig. 1a-d. Split sample comparison between the five methods with the HPLC method as reference method (x-axis).

Dashed line represents the line $y=x$; Solid line represents the linear regression line.

- mean of 4 determinations

$\square$ mean of 16 determinations (control urine)

$\times$ sample omitted for the linear regression analysis. 
Tab. 5. Lincar regression lines obtained with the comparison study and by varying the reference method and the concentration unit and by correcting for recovery differences. together with four results from the literature.

\begin{tabular}{|c|c|c|c|c|c|c|c|c|}
\hline No. & Lincar regres & ssion line & & & $n$ & $r$ & Concentration unit & Reference \\
\hline 1 & y (Bio-Rad) & $=14.5$ & $+0.83 x$ & (HPLC) & 11 & 0.9829 & $\mu \mathrm{mol} / \mathrm{l}$ & this article \\
\hline 2 & y (Pisano $)=$ & $=3.5$ & $+0.84 \times$ & (HPLC) & 12 & 0.9912 & $\mu \mathrm{mol} / \mathrm{I}$ & this article \\
\hline $3 *)$ & y (Pisano) & $=3.7$ & $+0.91 x$ & (HPLC) & 12 & 0.9912 & $\mu \mathrm{mol} / \mathrm{l}$ & this article \\
\hline 4 & $y$ (Pap.chr.) & $=3.9$ & $+1.07 x$ & (HPLC) & 12 & 0.9957 & $\mu \mathrm{mol} / \mathrm{l}$ & this article \\
\hline 5 & $y(G L C)$ & $=1.6$ & $+0.85 x$ & (HPLC) & 12 & 0.9927 & $\mu \mathrm{mol} / \mathrm{l}$ & this article \\
\hline $\left.6^{*}\right)$ & y (GLC) & $=1.7$ & $+0.90 x$ & (HPLC) & 12 & 0.9927 & $\mu \mathrm{mol} / \mathrm{I}$ & this article \\
\hline 7 & $y(G L C)$ & $=-1.9$ & $+1.01 x$ & (Pisano) & 13 & 0.9959 & $\mu \mathrm{mol} / 1$ & this article \\
\hline 8 & $y(G I, C)$ & $=-2.2$ & $+0.96 x$ & (Pisano) & 11 & 0.9650 & $\mu \mathrm{mol} / 24 \mathrm{~h}$ & this article \\
\hline 9 & $y$ (HPICC) & $=-3.6$ & $+1.16 x$ & (Pisano) & 12 & 0.9912 & $\mu \mathrm{mol} / \mathrm{l}$ & this article \\
\hline $10 *)$ & $y$ (HPLC) & $=-3.6$ & $+1.08 x$ & (Pisano) & 12 & 0.9912 & $\mu \mathrm{mol} / \mathrm{I}$ & this article \\
\hline 11 & $y$ (HPLC) & $=-3.3$ & $+1.04 x$ & (Pisano) & 10 & 0.9259 & $\mu \mathrm{mol} / 24 \mathrm{~h}$ & this article \\
\hline $\left.12^{*}\right)$ & $y$ (HPLC) & $=-3.2$ & $+0.97 x$ & (Pisano) & 10 & 0.9267 & $\mu \mathrm{mol} / 24 \mathrm{~h}$ & this article \\
\hline 13 & y (GLC) & $=21.7$ & $+0.62 x$ & (Pisano) & 224 & 0.844 & $\mu \mathrm{mol} / \mathrm{l}$ & (10) \\
\hline 14 & $y(G L C)$ & $=2.63$ & $+1.05 x$ & (Pisano) & 65 & 0.997 & $\mu \mathrm{mol} / 24 \mathrm{~h}$ & (15) \\
\hline 15 & y (HPLC) & $=0.61$ & $+1.06 x$ & (Pisano) & 41 & 0.997 & $\mu \mathrm{mol} / \mathrm{l}$ & (22) \\
\hline 16 & y (HPLC) & $=0.36$ & $+0.99 x$ & (Pisano) & 20 & 0.931 & $\mu \mathrm{mol} / 24 \mathrm{~h}$ & (27) \\
\hline
\end{tabular}

*) corrected for differences in recovery (see tab. 4).

Tab. 6. Results of the interference study with five methods.

3-Methoxy-4-hydrodroxymandelic acid ( $\mu \mathrm{mol} / \mathrm{l})$

\begin{tabular}{|c|c|c|c|c|c|c|}
\hline Interfering compound & $\begin{array}{l}\text { Concentration } \\
(\mathrm{mg} / \mathrm{l})\end{array}$ & GLC & Bio-Rad & Pisano & $\begin{array}{l}\text { Paper- } \\
\text { chromatography }\end{array}$ & HPLC \\
\hline None & - & 14.9 & 44.3 & 25.9 & 27.7 & 24.8 \\
\hline 3.4-Dihydroxyphenylacetic acid & 500 & a & 13.0 & 21.3 & 28.2 & 23.4 \\
\hline Homovanillic acid & 1000 & 14.8 & 136.9 & $9.2^{c}$ & 28.4 & 26.2 \\
\hline$p$-Hydroxymandelic acid & 100 & 15.2 & 249.9 & 52.8 & 27.4 & 23.8 \\
\hline Vanillic acid & 1000 & 14.8 & 46.3 & 26.7 & 31.0 & 24.8 \\
\hline Salicyluric acid & 1000 & 13.2 & 45.4 & 27.2 & 26.7 & 23.5 \\
\hline Gentisic acid & 1000 & 16.6 & 47.0 & 6.2 & 25.6 & 26.2 \\
\hline Homogentisic acid & 2000 & b & 43.6 & 5.6 & 23.0 & $27.8^{f}$ \\
\hline $\left.\begin{array}{l}\text { p-Aminosalicylic acid } \\
\text { 5-Hydroxyindoleacetic acid } \\
\text { Glycerylguaiacolate }\end{array}\right\}^{* *}$ & $\begin{array}{r}1000 \\
500 \\
1000\end{array}$ & c & $\begin{array}{l}40.8 \\
\text { and } \\
70.3^{d}\end{array}$ & 21.4 & $\begin{array}{l}41.8 \\
29.8 \\
23.4\end{array}$ & $21.3^{\mathrm{g}}$ \\
\hline $\begin{array}{l}\text { Phenylsulphonephthalein }\}^{*} \\
\text { Bromthalein }\end{array}$ & $\begin{array}{r}6 \\
350\end{array}$ & 13.7 & 43.1 & 27.5 & 26.4 & 23.6 \\
\hline
\end{tabular}

*: mixtures of these compounds were added to an aliquot of the pool urine.

a, b: the interfering compound was not separated from 3-methoxy-4-hydroxymandelic acid, because of their large difference in concentration.

c: 5-hydroxyindoleacetic acid was not separated from the internal standard propylgallate, because of the large difference in concentration between 5-hydroxyindoleacetic acid and propylgallate.

d: this difference could not be investigated because the Bio-Rad VMA by Column test was no longer available.

e: $500 \mathrm{mg}$ homovanillic acid gave a result of $7.7 \mu \mathrm{mol} / 1$ 3-methoxy-4-hydroxymandelic acid.

f: 3-methoxy-4-hydroxymandelic acid' was not fully separated from an impurity in the homogentisic acid preparation.

g: 5-hydroxyindoleacetic acid (eluting after 3-methoxy-4-hydroxymandelic acid, without interfering) deteriorated the electrode surface, resulting in a decreased detector response for the subsequent analysis. 


\section{Discussion}

Table 1 shows that differences between the 3methoxy-4-hydroxymandelic acid concentrations found by the five methods in the same urine sample cannot be attributed to differences in standardization, except for the GLC method. The results of the GLC method indicate that the mean recovery was $90.7 \%$, so all results should be corrected with this percentage. This was only done with the results of the linearity check, the recovery and the comparison study.

The results of the imprecision study (tab. 2) indicate that the within-run and between-days imprecision of the two classical methods are large compared with the other three methods. In the paper chromatographic method, this may be due especially to the sometimes non-optimal separation of 3-methoxy-4hydroxymandelic acid from very faint coloured spots of unknown compounds. The high coefficient of variation of the Pisano method is mainly due to difficulties in determining the urine blanks. In three out of eight series, we found that the absorbance of the urine blanks of the control urine were higher than normal. If a correction is made with the use of a mean urine blank value, we get the imprecision data placed between brackets in table 2 . The imprecision data are now comparable with those of the Bio-Rad, the HPLC and the GLC (only within-run CV) methods. The reason for these variations, especially in the urine blank, is unknown.

In the literature we could find data on the imprecision of the Pisano method from only one group of investigators: Wisser \& Stamm (between-days $\mathrm{CV}=4.8 \% ; \mathrm{n}=48 ; \quad \overline{\mathrm{x}}=18 \mu \mathrm{mol} / \mathrm{l} ;$ within-run $\mathrm{CV}=1.6 \% ; \mathrm{n}=48 ; \overline{\mathrm{x}}=18 \mu \mathrm{mol} / \mathrm{l})(36)$. They used a modified Pisano method for aliquoting the organic extraction solvents. Therefore we also compared our results with data from a quality control group of clin- ical chemical laboratories in the Netherlands, $P . J$. Brombacher (37), including laboratories using the original Pisano method.

The results of the between-days imprecision of the different methods are given in table 7 . Laboratories nos. 6, 7 and 8 performed the Pisano, the Bio-Rad and the paper chromatographic method, respectively in the comparison study. Table 6 shows that the mean value of the control urines (aliquoted urine pools, stored at $-20^{\circ} \mathrm{C}$ ) is almost the same for la= boratories nos. $1-6$, but the ranges of the betweendays $\mathrm{CV}$ are broad. Both imprecision data, corrected and uncorrected, lie between these ranges, but even the corrected $\mathrm{CV}$ is two times higher than that of laboratory 6 in table 7 .

Only the corrected results of the imprecision study of the Pisano method are comparable with the results of Wisser \& Stamm (36).

The between-days CV of the GLC method is high. This can be explained by the following facts. The GLC method, not performed in duplicate like the others, is not only a method for the determination of 3-methoxy-4-hydroxymandelic acid, but also of homovanillic acid, 3-methoxy-4-hydroxyphenylethylene glycol, 3,4-dihydroxyphenylacetic acid and 5hydroxyindoleacetic acid. This means that the analytical conditions are not optimally chosen for the determination of 3-methoxy-4-hydroxymandelic acid; the between-days CV of 3-methoxy-4-hydroxymandelic acid is always higher if the method includes an enzymatic hydrolysis, like the one necessary for the determination of 3-methoxy-4-hydroxyphenyl ethylene glycol, the between-days CV found for 3methoxy-4-hydroxymandelic acid is in good agreement with that given by Muskiet et al. in their original article (14) $(C V=14.3 \% ; n=20 ; \bar{x}=1.6$ $\mathrm{mmol} / \mathrm{mol}$ creatinine).

Tab. 7. Between-days CV of the 3-methoxy-4-hydroxymandelic acid determination in two aliquoted urine pools stored at $-20^{\circ} \mathrm{C}$ of 8 laboratories participating in a quality control group in the Netherlands, $P$. J. Brombacher (37).

\begin{tabular}{|c|c|c|c|c|c|c|c|c|c|c|}
\hline No. & Method & $\mathrm{n}$ & $\begin{array}{l}\bar{x} \\
(\mu \mathrm{mol} / \mathrm{l})\end{array}$ & $\begin{array}{l}\text { SD } \\
(\mu \mathrm{mol} / 1)\end{array}$ & $\begin{array}{l}C V \\
(\%)\end{array}$ & $\mathbf{n}$ & $\begin{array}{l}\overline{\mathbf{x}} \\
(\mu \mathrm{mol} / \mathrm{l})\end{array}$ & $\begin{array}{l}\text { SD } \\
(\mu \mathrm{mol} / \mathrm{l})\end{array}$ & & $\begin{array}{l}C V \\
(\%)\end{array}$ \\
\hline 1 & Pisano & 22 & 34 & 6.6 & 19.5 & 21 & 17 & 3.7 & & 22.6 \\
\hline 2 & Pisano & 18 & 35 & 2.2 & 6.4 & 18 & 14 & 1.3 & & 9.3 \\
\hline 3 & Pisano & 17 & 35 & 2.9 & 8.2 & 16 & $1 \dot{5}$ & 1.5 & & 9.6 \\
\hline 4 & Pisano & 19 & 41 & 4.6 & 11.0 & 18 & 18 & 2.0 & $\therefore$ & 11.0 \\
\hline 5 & Pisano & 8 & 33 & 4.9 & 15.0 & 8 & 14 & 1.4 & & 9.8 \\
\hline 6 & Pisano & 6 & 34 & 1.0 & 2.9 & 6 & 13 & 0.4 & & 3.2 \\
\hline 7 & Bio-Rad & 31 & 46 & 3.4 & 7.4 & 31 & 22 & 2.4 & & 10.6 \\
\hline 8 & Paperchromatography & 30 & 33 & 3.1 & 9.3 & 30 & 15 & 2.4 & & 15.7 \\
\hline
\end{tabular}

Laboratory nos. 6,7 and 8 are the same laboratories participating in this comparison study. 
The imprecision data of the Bio-Rad and the HPLC method are excellent. The within-run $\mathrm{CV}$ of the HPLC method is extremely low (1.4\%). Also for the Bio-Rad method a comparison of the imprecision data can only be made with the results of table 7 (laboratory no. 7), showing that the between-days $\mathrm{CV}$ is somewhat smaller in our comparison study.

Of those HPLC methods reporting quality control data, only the between-days imprecision of the HPLC method with a periodate oxidative monitor $(\mathrm{CV}=5.7$ and $6.1 \% ; \overline{\mathrm{x}}=25.0$ and $34.5 \mu \mathrm{mol} / 1$; $\mathrm{n}=8(28)$ ) is comparable with our results. All other HPLC methods $(21,25,27$ and 29) and even the method of Morrisey \& Shihabi (CV $=7.8 \%$; $\overline{\mathrm{x}}=70.0 \mu \mathrm{mol} / \mathrm{l} ; \mathrm{n}=19$ (23)), which was modified, show quality control data with larger imprecision than the HPLC method used in this study.

Moleman \& Borstrok (32) publish the following data of their own routine quality control: within-run $\mathrm{CV}$ : $3.0 ; 4.1 ; 2.0 \%$; between-days CV: $6.5 ; 4.9 ; 5.0 \%$; $\mathrm{n}=10 ; 11 ; 11 ; \overline{\mathrm{x}}=10.8 ; 43.2 ; 74.8 \mu \mathrm{mol} / 1$. These excellent imprecision data are achieved by the modified sample clean up and by calibrating the detector response and the retention time every six samples.

The results of the linearity check (tab. 3) show a good linearity for all five methods ( $\mathrm{r}$ ranging from $0.9943-0.9993$ ). However the slopes and the intercepts of the five regression lines are quite different. This means a difference in accuracy between the five methods. In order to investigate whether these differences were due to recovery problems, the same urine sample with low 3-methoxy-4-hydroxymandelic acid content was enriched with known quantities of 3-methoxy-4-hydroxymandelic acid. The results of these recovery studies, presented in table 4 , also show a good' linearity for all methods ( $\mathrm{r}$ ranging from $0.9931-0.9994)$. The mean recovery found with the GLC $(95.7 \%)$, the Pisano $(94.4 \%)$, the Bio-Rad $(96.0 \%)$ and the paper chromatographic method $(93.9 \%)$ are almost equal. The mean recovery found with the HPLC method $(101.3 \%)$ is somewhat better than the data obtained with the other methods. The HPLC method also shows the smallest standard deviation. These small differences in recovery cannot be responsible for the deviations found in the slopes and intercepts of the regression lines in table 3. Thus, we conclude that the accuracies of the five methods are unequal because of differences in the contribution of urinary compounds other than 3 methoxy-4-hydroxymandelic acid to the determination of 3-methoxy-4-hydroxymandelic acid.

This conclusion is also visualized in the figures $1 \mathrm{a}-\mathrm{d}$ presenting the results of the split sample comparison study. Figure 1 a clearly shows that the Bio-Rad method gives higher values, especially in the low concentration range. Sometimes the discrepancy is . very large: in one urine sample the HPLC method gives a 3-methoxy-4-hydroxymandelic acid value of $38.5 \mu \mathrm{mol} / \mathrm{l}$ and the Bio-Rad method gives a value of $73.4 \mu \mathrm{mol} / 1$ (mean of four determinations). This means that the contribution to the 3-methoxy-4-hydroxymandelic acid determination of other compounds in urine is very large and may vary from urine to urine. We did not clarify the nature of these compounds.

Figure $1 \mathrm{~b}$ and $1 \mathrm{~d}$ show that the correlation between the GLC, Pisano and HPLC method is reasonable ( $r=0.9912$ and 0.9929 respectively). Both the GLC and the Pisano method give higher values in the high concentration range. Even after correction for the recovery differences (see tab. 4), the Pisano method (values above $40 \mu \mathrm{mol} / \mathrm{l}$ ) and the GLC method (values above $17 \mu \mathrm{mol} / \mathrm{l}$ ) still give lower 3-methoxy4-hydroxymandelic acid values than the HPLC method (see also the linear regression lines no. 3 and 6 in table 5).

Taking the Pisano method as reference method, our split sample comparison results with the GLC method (linear regression line no. 7 in table 5) are better than those of Addanki et al. (linear regression line no. 13). Our results are in reasonable agreement with the results of Leiendecker-Foster \& Feier (see linear regression lines nos. 8 and 14).

The results of Felice \& Kissinger and of Bauersfeld et al., comparing their HPLC method with electrochemical detection with the Pisano method as reference method (linear regression lines nos. 15 and 16 respectively in table 5) correlate well with our linear regression lines nos. 10 and 12 respectively.

The correlation between the paper chromatographic method and the HPLC method is the best of all four comparisons $(r=0.9957)$. However the results of the paper chromatographic method are always higher than those of the HPLC method, but the differences are smaller than with the Bio-Rad method. In our own laboratory we made a more extensive comparison study between the HPLC and the paper chromatographic method using 101 urine samples. This study resulted in almost the same linear regression line: $y$ (paperchrom.) $=3.8+1.07 \times$ (HPLC), but with a poorer correlation coefficient: $r=0.9162$.

We have taken the HPLC method as reference method for the split sample comparison study because of the good results of the imprecision, linearity, recovery and interference study. However, as can 
be seen in figures $1 \mathrm{a}-\mathrm{d}$ the 3-methoxy-4-hydroxymandelic acid content of one urine sample indicated with $\mathrm{X}$ is overestimated by the HPLC method $(14.8 \mu \mathrm{mol} / \mathrm{l})$ compared with the other four methods $(6.2-12.1 \mu \mathrm{mol} / \mathrm{l})$. This was due to an unknown compound not fully separated from 3-methoxy-4hydroxymandelic acid.

Compounds which are known to interfere in different 3-methoxy-4-hydroxymandelic acid methods are found in the compilation of Young et al. (32). Such a compound can cause an in vivo interference because it intervenes in the catecholamine metabolism or a methodological interference. The physiological interference is of no interest in the comparison of 3methoxy-4-hydroxymandelic acid methods, so we only studied the methodological interferences. To aliquots of a pool urine, we added those compounds, which, according to the literature, are the real methodological interfering compounds. The amount of each interfering compound added to aliquots of the pool urine was largely based on abnormal levels seen in some disorders.

The results of the interference study (tab.6) show that the HPLC method is the only method free of interference from the compounds tested. Only 5-hydroxyindoleacetic acid caused some detector problems due to the high concentration, resulting in loss of, response. The GLC method sometimes has only separation problems due to too large a difference in concentration between the interfering compound and 3-methoxy-4-hydroxymandelic acid or the internal standard. In cases of pathological increases of 3,4-dihydroxyphenylacetic acid or 5-hydroxyindoleacetic acid, such problems are not encountered, as shown by the gas chromatograms of urines from patients with neuroblastoma and carcinoid tumour in figure 2 of 1.c. (14). Only an elevation of homogentisic acid in patients with alcaptonuria could perhaps give some problems in determining 3-methoxy-4-hydroxymandelic acid. The paper chromatographic method is only influenced by $p$-aminosalicylic acid, which produces an elevated background after staining. Correction with a blank including this elevated background prevents falsely elevated 3-methoxy-4hydroxymandelic acid results.
The Pisano and the Bio-Rad method are most sensitive for the interfering compounds tested. The influence of these compounds on the Pisano method, mentioned in table 6 , are in agreement with the results of Feldman et al. (38) and Pisano et al. (7). We did not find the decreasing influence of 3,4-dihydroxyphenylacetic acid as reported by Feldman et al. Whether the increase of the 3-methoxy-4-hydroxymandelic acid levels obtained by the Bio-Rad method caused by the addition of homovanillic acid and $p$-hydroxymandelic acid, and the decrease of the levels due to the addition of 3,4-dihydroxyphenylacetic acid, are relevant at more physiological concentrations could not be investigated because the Bio-Rad method was no longer available.

If we compare all methods studied, we can conclude that from an analytical point of view the HPLC and the GLC method are superior to the other three methods. Our final conclusion is that the HPLC method is the best method of choice for determining 3-methoxy=4-hydroxymandelic acid in urine, because of the better results of the imprecision study. However this larger imprecision of the 3-methoxy-4hydroxymandelic acid determination of the GLC catecholamine metabolite profiling method is compensated by the determination of more than one catecholamine metabolite. So it is possible that from a diagnostical point of view this HPLC method, determining only 3-methoxy-4-hydroxymandelic acid, will not be the method of choice. This problem of determining one metabolite very precisely or more metabolites with larger imprecision, which is possible with GLC (14) and HPLC (26) methods, must be the subject of further clinical chemical research.

\section{Acknowledgements}

We wish to express our thanks to: G. T. Berends, St. Elisabeth's of Groote Gasthuis, Haarlem, The Netherlands; P. Moleman, Department of Psychiatry, University Hospital Rotterdam Dijkzigt and Erasmus University, Rotterdam, The Netherlands; $F . A . J$. Muskiet, University Hospital Groningen, The Netherlands and $R$. K. A. van Wermeskerken, Diakonesseninrichting Bronovo, The Hague, The Netherlands, for participating in this comparison study.

The technical assistance of Miss $H$. J. Brouwer in organizing the comparison study is gratefully acknowledged.

\section{References}

1. Armstrong, M. D. \& McMillan, A. (1957) Fed. Proc. 16, 146.

2. Armstrong, M. D., McMillan, A. \& Shaw, K. N. F. (1957) Biochim. Biophys. Acta 25, 422-423.

3. Muskiet, F. A. J., Thomasson, C. G., Gerding, A. M., Fremouw-Ottevangers, D. C., Nagel, G. T. \& Wolthers, B. G. (1979) Clin. Chem. 25, 453-460.

4. Armstrong, M. D., Shaw, K. N. F. \& Wall, P. E. (1956) J. Biol. Chem. 218, 293-303.

5. Sandler, M. \& Ruthven, C. R. J. (1959) Lancet $I I, 114-115$ and 1034.

6. Sunderman, F. W., Jr., Cleveland, P.: D., Law, N. C. \& Sunderman, F. W. (1960) Amer. J. Clin. Pathol. 34; 293312. 
7. Pisano, J. J., Crout, J. R. \& Abraham, D. (1962), Clin. Chim. Acta 7, 285-291.

8. van de Calseyde, J. F., Scholtis, R. J. H., Schmidt, N. A. \& Leyten, C. J. J. A. (1971) Clin. Chim. Acta 32, 361-366.

9. Roginsky, M. S., Gordon, R. D. \& Bennett, M. J. (1974) Clin. Chim. Acta 56, 261-264.

10. Addanki, S.. Hinnenkamp. E. R. \& Sotos, J. F. (1976) Clin. Chem. 22, 310-314.

11. Melchert. H.-U. \& Hoffmeister, H. (1977) J. Clin. Chem. Clin. Biochem. 15, 81-87.

12. Muskiet, F. A. J., Fremouw-Ottevangers, D. C., Wolthers, B. G. \& de Vries. J. A. (1977) Clin. Chem. 23, 863-867.

13. Brewster, M. A., Berry, D. H. \& Moriarty, M. (1977) Clin. Chem. 23, 2247-2249.

14. Muskiet, F. A. J., Stratingh. M. C.. Stob, G. J. \& Wolthers, B. G. (1981) Clin. Chem. 27, 223-227.

15. Leiendecker-Foster, C. \& Freier, E. F. (1981) Clin. Chem. 27, 2029-2032.

16. Yoshiue, S.. Yoshioka, M. \& Tamura. Z. (1975) Chem. Pharm. Bull. 23, 3040-3041.

17. Chauhan, J. \& Darbre, A. (1980) J. Chromatogr. 183, 391401.

18. Molnár, I., Horváth, C. \& Jatlow, P. (1978) Chromatographia $11,260-265$.

19. Bertani-Dziedzic, L. M., Krstulovic, A. M., Ciriello, S. \& Gitlow, S. E. (1979) J. Chromatogr. 164, 345-353.

20. Taylor, J. T. \& Freeman, S. (1981) Chromatography Newsletter 9, 1-4.

21. Yamada, K., Kayama, E. \& Aizawa, Y. (1981) J. Chromatogr. 223, 176-178.

22. Felice, R. J. \& Kissinger, P. T. (1977) Clin. Chim. Acta 76, $317-320$.
23. Morrisey, J. L. \& Shihabi, Z. K. (1979) Clin. Chem. 25. 2043-2045.

24. Krstulovic, A. M., Zakaria, M., Lohse, K. \& Bertani-Dziedzic, L. (1979) J. Chromatogr. 186, 733-748.

25. Soldin, S. J. \& Hill, J. G. (1980) Clin. Chem. 26, 291-294.

26. Joseph, M. H., Kadam, B. V. \& Risby, D. (1981) J. Chromatogr. 226, 361-368.

27. Bauersfeld, W.. Diener, U., Knoll, E., Ratge, D. \& Wisser, H. (1982) J. Clin. Chem. Clin. Biochem. 20, 217-220.

28. Rosano, T. G. \& Brown, H. H. (1979) Clin. Chem. 25, 550554.

29. Flood, J. G., Granger, M. \& McComb, R. B. (1979) Clin. Chem. 25, 1234-1238.

30. Moleman, P. \& Borstrok, J. J. M. (1983) Clin. Chem. 29. 878-881.

31. Vahidi, A., Roberts, H. R., San Filippo, J., Jr. \& Siva Sanhar, D. V. (1971) Clin. Chem. 17, 903-907.

32. Young, D S., Pestaner, L. C. \& Gibberman, V. (1975) Clin. Chem. 21, 1D-432D.

33. Instruction manual Bio-Rad VMA by Column Test. Catalog $191-8001$.

34. Molenaar, A. J. (1963) Boerhavecursus 19, Leiden, Hypertensie, sept. 1963, 310-315.

35. Armitage, P. (1971) Statistical Methods in Medical Research, Blackwell, Oxford.

36. Wisscr, H. \& Stamm, D. (1970) J. Clin. Chem. Clin. Biochem. 8, 21-26.

37. Brombacher, P. J. personal communication.

38. Feldman. J. M., Butler, S. S. \& Chapman. B. A. (1974) Clin. Chem. 20. 607-610.

Drs. C. G. Thomasson

Algemeen Ziekenhuis

"de Tjongerschans"

Thialfweg 44

NL-8441 PW Heerenveen 
